\title{
Abstract Styles in the Vienna Workshop: A Formalist Analysis of Josef Hoffman's Two Designs
}

\author{
Asli Arpak \\ Massachusetts Institute of Technology, \\ Cambridge, MA, USA \\ aarpak@mit.edu
}

\begin{abstract}
A shape grammar formalism is elaborated for the Vienna Workshop (Wiener Werkstaette) designer Josef Hoffmann's two designs. Early instances of abstract expressionism are traced in Hoffman's works by investigating stylistic parallels through shape rules and computations. The analysis of Hoffmann's two works are carried out in parallel to Terry Knight's analysis of De Stijl artists Georges Vantongerloo and Fritz Glarner paintings with the normal form grammars.
\end{abstract}

Keywords: Josef Hoffmann; Wiener Werkstaette; shape grammars; abstraction; style.

\section{Introduction}

In the end of the nineteenth century, many significant philosophical and artistic movements flourished in Europe that were fuelled by newly developing universal ideals, changing political scenes, and constant scientific and industrial advancements. Subsequent to the French Art Nouveau, impressionism, and the English Arts and Crafts Movement, a large group of Austrian artists and designers started the Vienna Workshop (Wiener Werkstaette) in 1903 with the Wagnerian ideal Gesamtkunstwerk (total artwork).

Various great Austrian architects, artists, and designers were affiliated with the Vienna Workshop and they soon developed a highly unique artistic style, always preserving the aims to make the arts accessible to everyone and to rethink designs with the considerations of the crafts and the developing industrialism. Therefore, the Workshop held a strong focus on the applied arts within the framework of various design fields, such as architecture, interior design, furniture, textiles, metalwork, ceramics, wood, glass, fine arts, jewellery, and fashion.

In the active years of the Vienna Workshop (1903-1932), the designers cultivated various artistic forms and styles in a variety of media. This paper argues that in the early Vienna Workshop designs, there were preceding elements of the constructivist and abstract art that became internationally significant with the intensive work of the French modernists, the Bauhaus, and the De Stijl in subsequent years. This paper employs shape grammar formalism and examines two small-scale design works of the great Vienna Workshop architect Josef Hoffmann (1870-1956) with the aim of externalizing these earlier elements and compositional principles of abstraction in the Vienna Workshop setting.

\section{Kabaret Fledermaus and the Architectural Detailing of Ceramics}

Kabaret Fledermaus (the Fledermaus Cabaret) was a theatre that opened in 1907 in the lively Vienna city and it was envisioned to be a meeting point for the Vienna avant-garde and the intelligentsia. The cabaret could house three hundred guests and its aim was to restore the cabaret culture with an artistic twist. In addition to restaging classical plays with new décor and costumes, the Vienna Workshop artists were also producing novel performances.
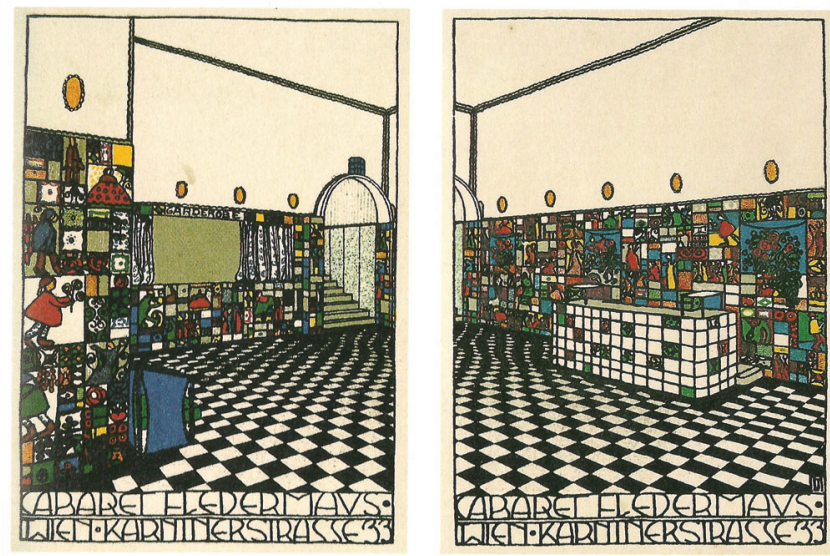

Figure 1: Illustration for the bar room at the Cabaret Fledermaus. Design supervised by Josef Hoffmann, 1907. Ceramics by Berthold Löffler and Michael Powolny, 1907. Postcard design attributed to Josef Diveky, 19071908. Copyright: IMAGNO/Austrian Archives. 
Together with the plays, Kabaret Fledermaus was a huge undertaking for the Vienna Workshop. The artists designed all the rooms and crafted all the furnishings, ranging from interior design elements such as furniture, kitchenware, cutlery, and lighting fixtures; to graphic design work, such as posters, letter and envelope templates, and event programs. The immense project was taken on by many of the Workshop designers, including Josef Hoffmann, Berthold Löffler, Michael Powolny, Carl Otto Czeschka, Moriz Jung, Oskar Kokoschka, and Fritz Zeymer. Such rigorous enterprise has established the Kabaret Fledermaus as one of the emblematic works of the Vienna Workshop throughout the century.

In the building's design, the architectural detailing of the entrance hall to the auditorium was realized by Josef Hoffmann. The walls of the room are covered with several thousand glazed ceramic tiles (Figure 1). The ceramic work was handled by Berthold Löffler and Michael Powolny at the Wiener Keramik. The ceramic tiles are adorned with a variety of compositions, such as caricatures, portraits, human figures, animal figures, abstract shapes, ornamental patterns, and singular colours.

When looked closely, we can observe that the organization of the ceramic tiles on the walls follow a subdivision pattern applied recursively. Grammatically, this subdivision pattern is reminiscent of the traditional Chinese ice-ray designs as studied by Stiny (1977), and the abstract compositions of the De Stijl artists as analysed by Knight (1989a). Stiny has shown the generation of traditional Chinese ice-ray designs via a simple set of shape rules in a shape grammar. Knight studied the abstract paintings of Georges Vantongerloo and Fritz Glarner utilizing normal form grammars and laid down the groundwork for formal analyses implemented in this paper.

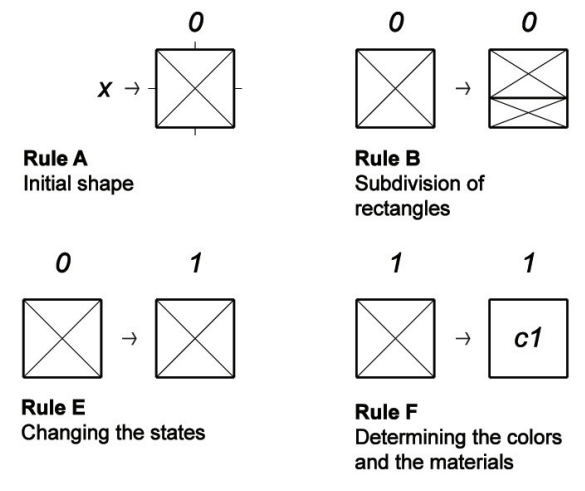

\section{The Shape Grammar Analysis}

As Knight (1989a) develops, we can perform shape grammar analyses utilizing the normal form grammars. In these grammars, there are spatial and non-spatial rules. The spatial rules define the relationships of shapes to each other, and the non-spatial rules specify procedures that are needed to be able to execute the grammar. These types of rules include operations for the initiation of shapes, assigning labels and stages, and ending the calculations.

For the analysis of the Kabaret Fledermaus ceramic wall, this paper follows Knight's grammar for the generation of Vantongerloo's and Glarner's abstract paintings. In the Fledermaus grammar, there are six rules (Figure 2) and these rules are applied parametrically and recursively. The calculation exemplified here (Figure 3) is based on the left section of the wall in Josef Diveky's illustration, which is shown closest to the spectator. The analysis can also be performed on other parts of the wall composition using the same grammar.

This analysis suggests that the designers and builders of the entrance hall - Hoffmann, Löffler, and Powolny - were experimenting with the subdivision rules as a compositional technique. Using Knight's grammar allows me to argue that some of the early works in the Vienna Workshop in this 1907-1908 period display stylistic precursors to the abstract compositions of the subsequent artistic work, such as those of the exemplary De Stijl artists Mondrian, Van Doesburg, Vantongerloo, and Glarner. However, it was not until later in the 1910s that the abstract art achieved further recognition, and these early dealings prove that the Vienna Workshop was stylistically ahead of its time and was foreseeing the orientations towards such abstractionism. Today, many scholars support the idea that Vienna is among the most important places for the birth of Modernism, along with Paris and Berlin. For the abstract modernist art, this also seems to hold true.

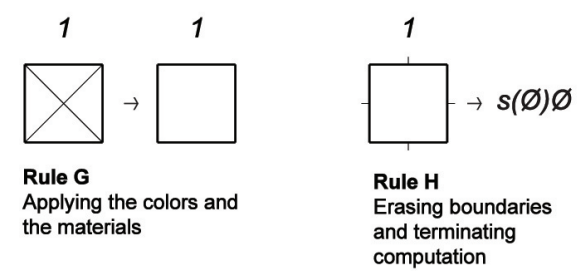

Figure 2: The Fledermaus grammar. Shape grammars for the derivation of ceramic tiles composition. 


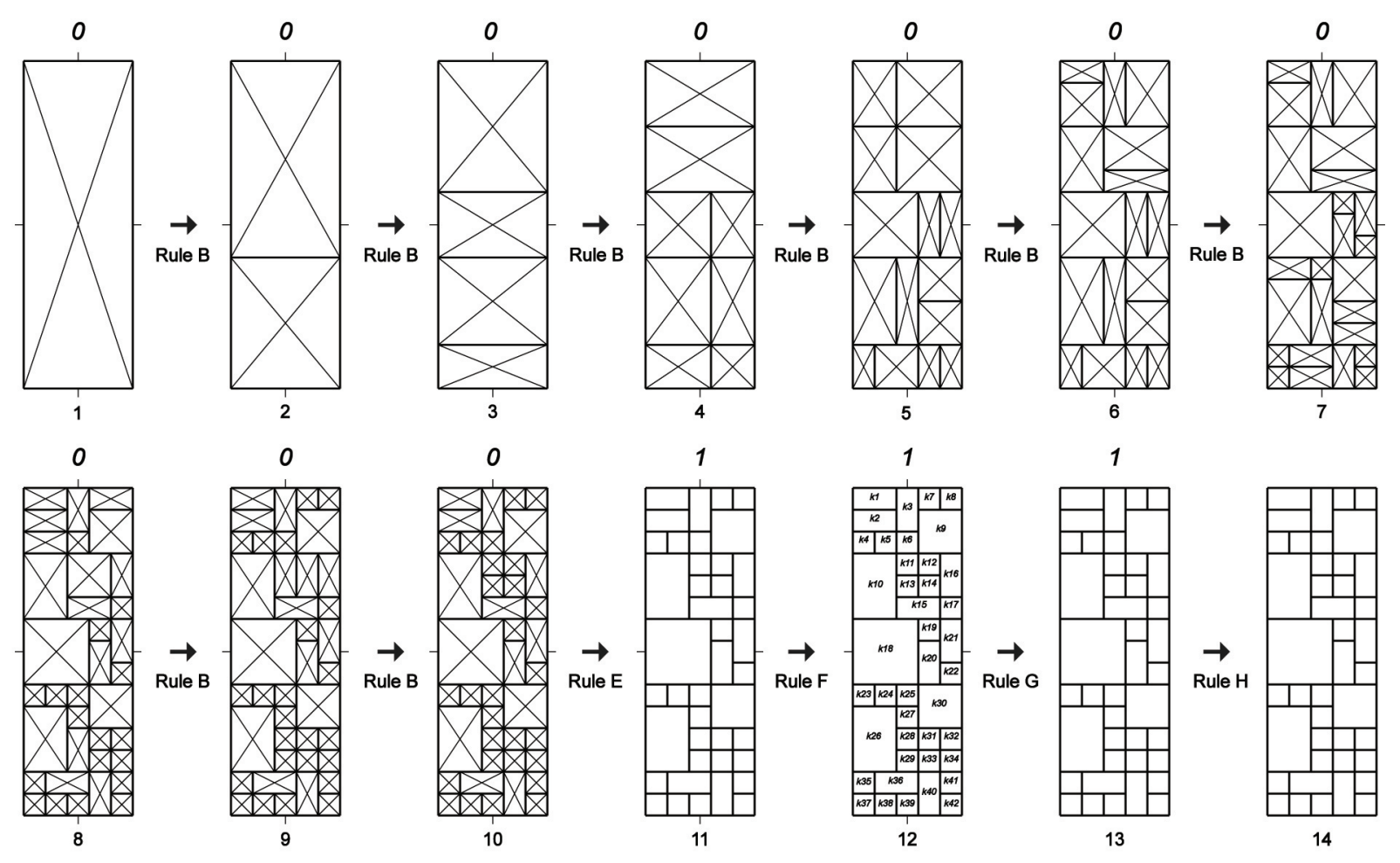

Figure 3: Calculation of a design with the Fledermaus grammar for part of the wall in the Kabaret Fledermaus entrance hall.

The Kabaret Fledermaus was unfortunately destroyed in 1945, however, Löffler's photograph of the entrance hall (Brandstaetter, 2003 , p.102) still survives. When we inspect the photograph closely, the ceramics application can be observed more in detail. Firstly, there is a big variety of the tile sizes and this variety seems to be consistent with some decorative decisions. The bigger tiles are frequently used to exhibit the scenic and figurative decorations. In some dense parts, the subdivision continues until a very small tile size is reached and these tiles are commonly decorated with individual colors. Interestingly, some of the midsized tiles follow the subdivision principles in themselves. We see further subdivisions and geometrically fitting pat-terns on the decorations.

This work compositionally displays that the subdivision rules allowed the artists to comprehensively exercise the ideas of scale, recursion, variety, and decoration. It also points at the mindfulness of such interplays, which seems to play a big role in bringing the arts and crafts together. The compositional and computational principles seem to have aided the artists to realize this ideal while maintaining the visual style.

\section{Planes and Colors on the Coffeepot Design}

Josef Hoffmann was the co-founder of the Vienna Workshop with Koloman Moser and he was a very influential and productive architect both in the Workshop and in his private commissions. Although he mostly associated with being an architect, he widely worked on industrial and crafted objects throughout his career. He particularly designed furniture, lighting, kitchenware, tableware and experimented extensively with wood, silver, ceramics, and glass.

In one of these undertakings, he designed a number of coffeepots and coffee cups. In his design sketch from 1928 (Figure 4), we can see that he relied on familiar subdivision principles in creating the colored decoration. Indeed, the same set of rules used in the analysis of Kabaret Fledermaus ceramics can help us analyze this design with two additional rules that allow us to combine two rectangles (Rule $C$ ) and to combine an $n$-gon $(n>4)$ with a rectangle (Rule

D)

(Figure

5).

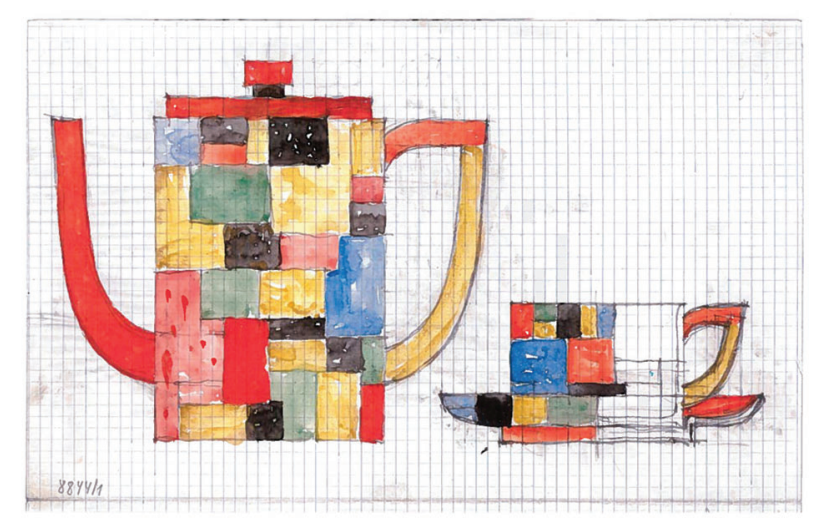

Figure 4: Josef Hoffmann's coffeepot and cup design, 1928 (Hoffmann, 1992, p.240.) Copyright: Austrian Museum of Applied Arts, Vienna (MAK). 

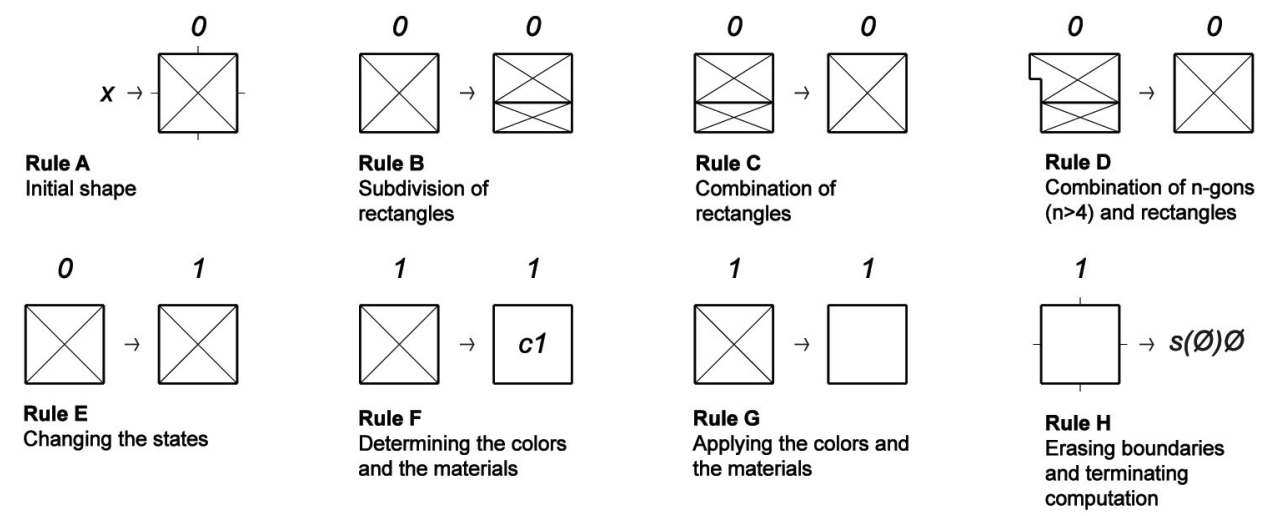

Figure 5: The coffeepot grammar. A shape grammar for Hoffmann's coffeepot and coffee cup design dated 1928.

Again, the rules are applied parametrically and recursively in the derivation of designs with the coffeepot grammar (Figure 6). It is also important to note that in both the Fledermaus grammar and the coffeepot grammar, we manipulate the planes; in shape grammar terms, we operate in the algebra U22. The left side of the rule takes the input as a plane, and the right side of the rule indicates a division or combination among the planes that are operated on.

These grammars can also be described in alternative ways. For instance, the grammars can be described where only lines are could also indicate algebra changes from U11 to either U12 or U22. They can also be combined with additional color rules or color grammars (Knight, 1989b). Shape grammars offer great flexibility in the design of rules themselves, therefore allows for design creativity with many alternative rule applications and computations.

If we revisit Hoffmann's sketch, he seems to be following a manipulation of planes that looks similar to our calculation. He subdivides the planes as the design proceeds, and he applies the colors as a coating layer after that part of the subdivision is completed. There are cases where adjacent areas are colored with the same color; therefore they visually seem to merge. grammar can include additional rules for stage changes, which

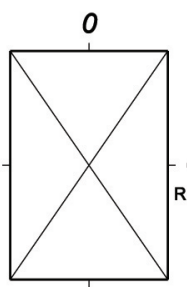

1

0

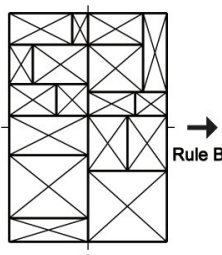

8

0

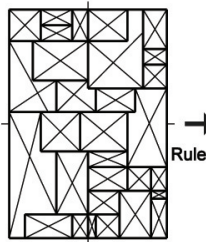

15

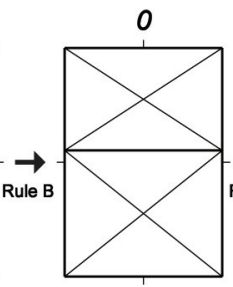

2

0

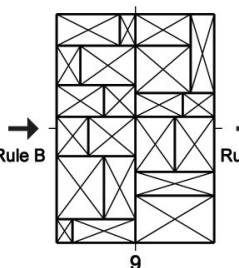

0

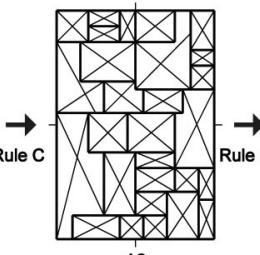

16

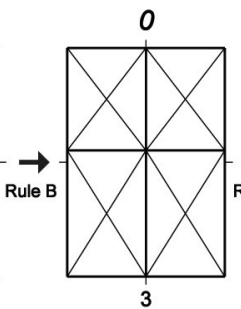

0

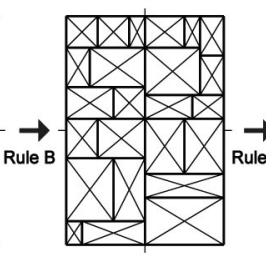

10

1

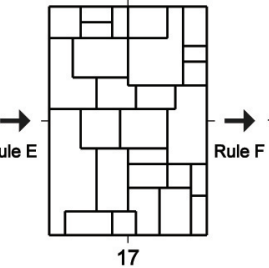

17

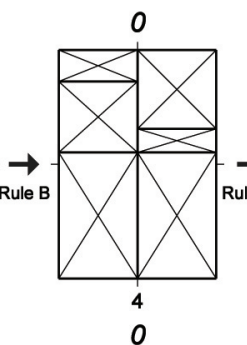

0
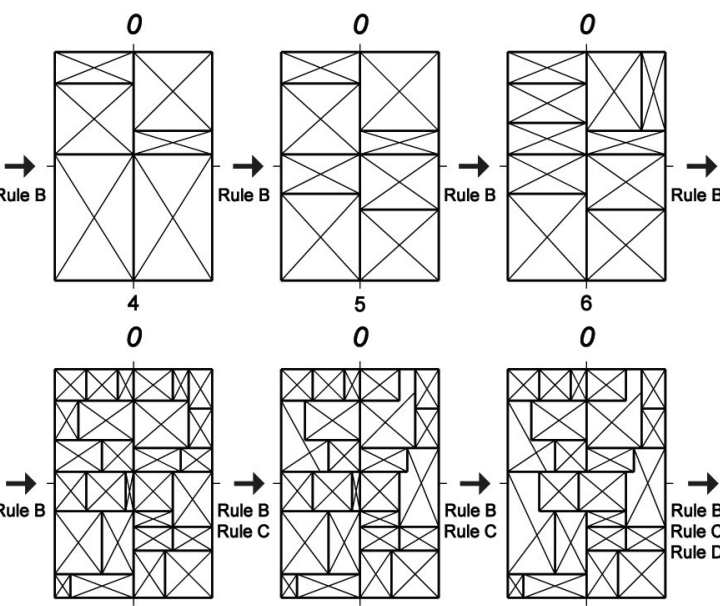

11

1

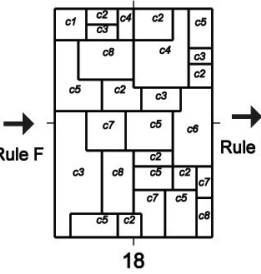

18
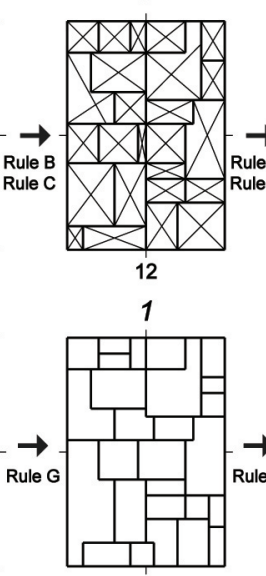

19

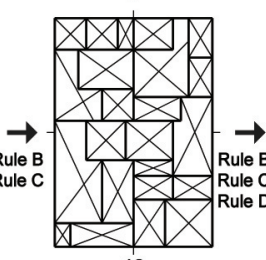

13

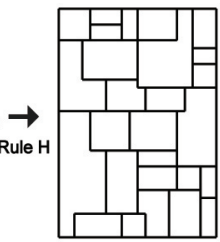

20

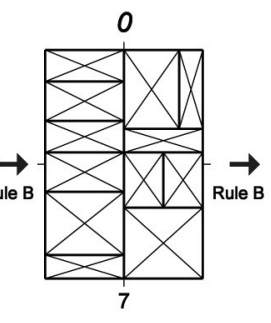

0

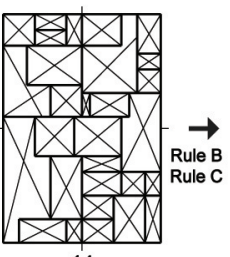

14

Colors

c1: violet
c2: black

c3: light red

c4: light yellow

c5: dark yellow

c6: blue

c7: green

c8: dark red

Figure 6: Derivation of Hoffmann's coffeepot design using the coffeepot grammar. 
In these areas, no particular attention is given to the actual subdividing lines and they do not seem to take part in the finished composition. In the unfinished part of the sketch with the coffee cup, we can see the subdivision process and the coloring of the layers more clearly.

Evidently, this sketch belongs to the later years of the 1920s when the European abstract art was fully recognized and Hoffmann might as well be experimenting with the new artistic styles in this period of his work. However, as the shape grammar analyses suggest, he already was applying some rule applications and computational principles in his early work in the 1903-1908 period. Indeed, it is very interesting to see Emil Hoppe's coloured lithograph portraying the 1908 Kunstschau Pavilion (designed by Hoffmann) illustrating the Vienna Workshop flag bearing an abstract composition of red-blue-yellow rectangles (Schweiger 1984 , p.83). Similarly, in some of the works of Hoffmann's close friend Gustav Klimt, especially the "Portrait of Adele Bloch-Bauer I" (1907), "The Kiss" (1907-1908), and the "Tree of Life" (1909), there are stylistically parallel elements and ornamentations. It is very remarkable that some of these paintings and mosaics were produced for the Stoclet Palace, which was one of the architectural masterpieces of the Vienna Workshop, in close acquaintance with its architect Josef Hoffmann.

\section{Conclusion}

The formalistic analyses of the two small-scale works of the Vienna Workshop architect Josef Hoffmann demonstrate that there were early dealings with the principles of abstract composition in the 1903-1910 period. The analyses were implemented on two compositions: the ceramics in the entrance of the Kabaret Fledermaus (1907) and a coffeepot design (1928). Both works can be derived with the shape grammars composed of similar subdivision and combination rules. It is presented that these works appear different but they have similar underlying principles with each other and with other well-known abstract paintings of the century. The computational correspondences permitted the designers to establish visual styles as well as mutual exchange between artistic and crafting considerations.

\section{References}

Brandstaetter, C. (2003). Wiener Werkstaette, design in Vienna 1903-1932: Architecture, furniture, commercial art, postcards, bookbinding, posters, glass, ceramics, metal, fashion, textiles, accessories, jewelry. New York: Harry N. Abrams.

Hoffmann, J. F. (1992). Josef Hoffmann designs : MAK-Austrian Museum of Applied Arts, Vienna. Edited by P. Noever. Munich, Germany: Prestel.

Kallir, J. (1986). Viennese design and the Wiener Werkstätte, G. Braziller, in association with Galerie St. Etienne, New York.

Knight, T. W. (1989a). Transformations of De Stijl art: the paintings of Georges Vantongerloo and Fritz Glarner. Environment and Planning B, 16(1), 51-98.

Knight, T.W. (1989b). Color grammars: designing with lines and colors. Environment and Planning B, 16(4), 417-449.

Martin, J. L.; Nicholson B.; and Gabo, N. (Eds.) (1971). Circle: international survey of constructive art. New York: Praeger Publishers.

Schweiger, W. J. (1984). Wiener Werkstaette: design in Vienna, 1903-1932. New York: Abbeville Press.

Stiny, G. (1977). Ice-ray: a note on the generation of Chinese lattice designs. Environment and Planning B, 4(1), 89-98. 